\title{
Acute Infectious Cervical Lymphadenitis of Children in A Tropical Country
}

\author{
Ngor Ndour, Souleymane Maiga*, Ahmadou Cheikhou Sall, Ndongo Pilor, Houra Ahmed and Issa Cheikh Ndiaye \\ Lamine Sine Diop Clinic, Fann Teaching Hospital, Dakar, Senegal
}

*Corresponding author: Souleymane Maiga, Lamine Sine Diop Clinic, Fann Teaching Hospital, Dakar, Senegal

\begin{abstract}
Introduction: The volume increase of a cervical lymph node is frequent in infancy .It is most often secondary to a benign infection of the upper aerodigestive tracts [1,2]. It is a medical and surgical emergency frequently encountered in developing countries, despite the generalization of antibiotics. Its gravity depends on the virulence of the germ and the fragility of the patient.

Patients and Methods: It's about a retrospectively study of all the medical files records of patients under 16 years old hospitalized at the ENT department of Fann Teaching Hospital for the management of infectious cervical lymphadenitis . The studied period is January 1st, 2008 to November 30th, 2017.

Results: We had collected 83 medical files of patients with acute infectious cervical lymphadenitis including 66 cases of suppurative acute lymphadenitis and 17 cases of simple acute adenitis (uncollected). The average age of our patients was 2.4 years with extremes ranging from 1 month to 16 month. The location of swelling was the submandibular region in 57 patients, upper jugular area in 8 patients and submental region in 6 patients. Stapphyloccocus aureus is the most frequent bacteria found in 29 cases. Initial antibiotic therapy consisted of the association of amoxicillin/clavulanic. A favorable evolution marked by an apyrexia after $48 \mathrm{~h}$ of treatment with regression of the swelling and a resumption of the feeding was noted in $92 \%$ of the cases. We deplored two cases of death.

Conclusion: Acute adenitis is frequent in pediatric otorhinolaryngology. It is often secondary to oropharyngeal infections, dental and skin diseases. The treatment is essentially based on antibiotics.
\end{abstract}

Keywords: Acute lymphadenitis; pediatric infection; cervical lymph's nodes

\section{Introduction}

The volume increase of a cervical lymph node is frequent in infancy .It is most often secondary to a benign infection of the upper aerodigestive tracts $[1,2]$. It is a medical and surgical emergency frequently encountered in developing countries, despite the generalization of antibiotics. Its gravity depends on the virulence of the germ and the fragility of the patient [3]. The aim of our study was to describe the epidemiological, clinical, and therapeutic aspects of acute infectious cervical lymphadenitis of the children in the Otorhinolaryngology - Head and Neck surgery department of Fann Teaching Hospital in Dakar, Senegal.

\section{Patients and Methods}

We studied all the medical records of patients less than 16 years old hospitalized in our ENT department for the management of infectious cervical lymphadenitis that occurred for less than 30 days. The studied period is January $1^{\text {st }}, 2008$ to November 30th, 2017. We excluded all incomplete medical records and patients treated on an outpatient basis. We collected in all records, age, gender, past medical history, duration of evolution, physical examination data, paraclinical data, treatment, and evolution.

\section{Results}

\section{The epidemiological aspects}

During the study period, we collected 83 medical records including 66 cases of suppurative acute lymphadenitis and 17 cases of simple acute adenitis (uncollected). The average age of our patients was 2.4 years with extremes ranging from 1 month to 16 years and the median was 1.5 years. Patients aged less than 5 years 
accounted for $89.15 \%$ of cases (Figure 1). There were 45 boys and 38 girls, a sex ratio of 1.1 .

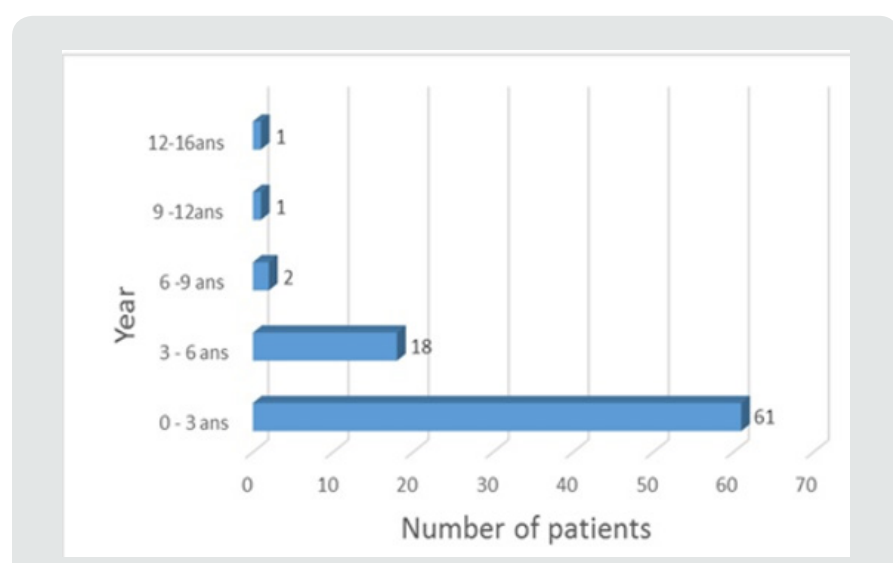

Figure 1: Histogram of patients by age.

\section{The diagnostic aspects}

The time between onset of cervical swelling and admission ranged from 1 to 25 days with an average of 8.75 days. All our patients present with an inflammatory lateral cervical swelling, the other associated clinical signs were detailed in Table 1. An infectious syndrome was present at the time of diagnosis in $80.72 \%$ of cases. The location of swelling was the submandibular region in 57 patients (Figure 2), upper jugular area in 8 patients, submental region in 6 patients and not specified in 12 patients. Portal of entry was nasopharyngeal in $66.26 \%$ of cases, cutaneous in $7.3 \%$ of cases and in $26.50 \%$ of cases, it was not found. Three patients in our series underwent adenoidectomy. A cervical ultrasound was performed in 14 patients whose needle aspiration was unsuccessful. It showed suppuration in 6 cases and in the remaining 8 patients it showed cervical non-necrotic lymphadenitis. Biologically, leukocytosis was noted in 29 patients and the average CRP was 64.88 milligrams (mg) with extremes ranging from $12 \mathrm{mg} / \mathrm{l}$ to $216.13 \mathrm{mg} / \mathrm{l}$. A field assessment (glycemia, creatine, HIV serology) was performed in $14 \%$ of patients and was without particularities. Fine needle aspiration in all patients brought pus in 66 cases. Of these 66 samples, 56 bacteriological results were found. Isolated organisms were methicillin-resistant Staphylococcus aureus ( $n=29)$, group A streptococcus $(n=9)$ and decapitated infection $(n=21)$ (Table 2).

Table 1: Clinical signs at time of admission.

\begin{tabular}{|c|c|}
\hline Clinical Signs & Numbera of Patients \\
\hline Lateral neck pain & 83 \\
\hline Rhinorrhea & 25 \\
\hline Nasal obstruction & 15 \\
\hline Mouth breathing & 9 \\
\hline Torticollis & 3 \\
\hline Breast-feeding refusal & 12 \\
\hline Incessant tears & 18 \\
\hline Swelling & 83 \\
\hline
\end{tabular}

\begin{tabular}{|c|c|}
\hline Tonsillar hypertrophy & 9 \\
\hline Cervical lymphnodes & 21 \\
\hline Fever & 72 \\
\hline
\end{tabular}

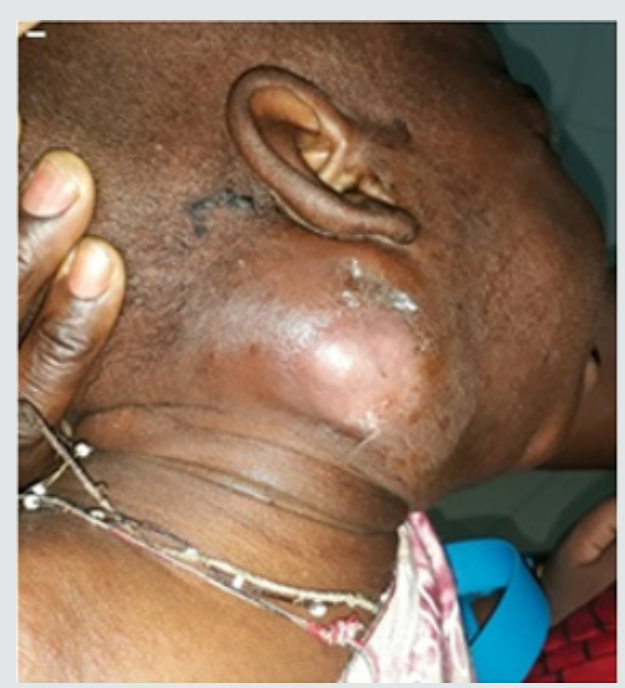

Figure 2: Fluctuating right submandibular swelling.

Table 2: Germs identified by antibiogram.

\begin{tabular}{|c|c|c|}
\hline Germs & Percentage & Antibioticsensitivity \\
\hline $\begin{array}{c}\text { Staphylococcus } \\
\text { aureus }\end{array}$ & $44,64 \%$ & $\begin{array}{c}\text { Oxacillin, gentamicin, } \\
\text { erythromycin, chloramphenicol }\end{array}$ \\
\hline $\begin{array}{c}\text { Group A } \\
\text { Streptococcus }\end{array}$ & $16,07 \%$ & $\begin{array}{c}\text { Amoxicillin/clavulanicacid, } \\
\text { ceftriaxone, pefloxacine, } \\
\text { gentamicin, chloramphenicol }\end{array}$ \\
\hline No germ found & $39,28 \%$ & \\
\hline
\end{tabular}

\section{Therapeutic aspects}

The majority of patients (61.44\%) had received oral antibiotic treatment, based on amoxicillin and cotrimoxazole, prescribed in others hospital before admission. And incision with drainage under local anesthesia was performed in the cases where the tumefaction was collected. The average amount of drained out pus was $17.6 \mathrm{ml}$ with extremes of $3 \mathrm{ml}$ to $70 \mathrm{ml}$. Medical treatment alone was initiated in cases of uncollected swelling. Initial antibiotic therapy consisted of the association of amoxicillin/clavulanic acid with adjuvant therapy (analgesic, nasal lavage, and iron supplementation). The average duration of hospitalization was 5 days with extremes of 3 to 11 days. A favorable evolution marked by a stable apyrexia after $48 \mathrm{~h}$, a regression of the swelling and a resumption of the feeding was noted in $92 \%$ of the cases. However, we noted cases of complications like a necrotizing dermo-hypodermis's $(n=1)$ (Figure $3)$, myositis $(n=1)$, keloid scar $(n=1)$ and one recurrence. In our series, two cases of death were deplored, the first case of death was a 3-month-old infant who presented a cervical lymphadenitis and a retropharyngeal abscess with a syndrome of severe respiratory distress motivating an emergency tracheotomy but the child already had hypoxemia and he died. The second case of death was septic shock with multi-visceral failure. Adenoidectomy with or 
without tonsillectomy was performed remotely within an average of 1.5 months after hospital discharge in $28 \%$ of cases.

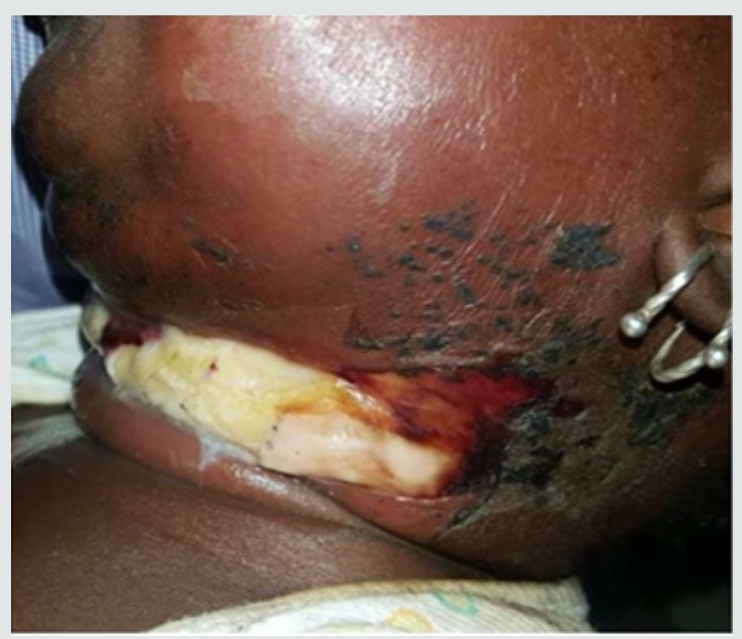

Figure 3: Necrotizing dermo-hypodermitis complicating a cervical lymphadenitis.

\section{Discussion}

\section{The epidemiological aspects}

Acute cervical adenitis is a common condition in tropical environments. It is often benign and is mainly of interest to the pediatric population. In our study, we found a median age of 2.4 years which corroborates the data of the literature $[1,4,5]$. The majority of patients in our series (89.15\% of the cases) were under 5 years old. Beyond this age the incidence decreases sharply due to progressive atrophy of the cervical lymph's nodes, a decrease of upper respiratory tract infections secondary to maturation of the immune system [4-7]. Male prevalence found in our work (or $54 \%$ of the cases) is a statement shared with other authors [1,4-6], without any physio pathological explanation that can be made to this observation.

\section{The clinical and paraclinical aspects}

The relatively long consultation delay is due to the fact that many patients go first to the traditional healers. This is explained by the substantial under-medicalization in our context and the low socio-economic level [4]. The classical clinical presentation is dominated by an inflammatory-type cervical swelling (pain, heat, redness) associated with an infectious syndrome [8-10]. These signs were found in all our patients. The association with acute nasopharyngitis at the time of diagnosis is frequent because it is most often the gateway. It is present in our work in $39.7 \%$ of cases which is consistent with the results of the literature [3-5,9,11]. Some nonspecific signs, such as general state deterioration, anorexia, and stiffness of the head, may be prominent in infants [11]. The existence of a fluctuation of ganglionic swelling is in favor of suppurative adenitis. Diagnosis of suppurative adenitis will be confirmed by the presence of pus during the fine needle puncture which opposes it to the acute adenitis not collected. When the ganglionic hull is thick because of a large peri adenitis, the diagnosis is more difficult $[1,12,13]$. Some authors recommend a systematic ultrasound to highlight the collection in the form of a hypoechoic pad with posterior reinforcement before considering an exploratory puncture of the ganglion $[1,12,13]$.

Tomodensitometry is less interesting because it does not differentiate between early necrosis and purulent collection and can lead to diagnoses in excess [1,2]. Cervical tomodensitometry for a complication (abscess to drain, venous thrombosis) is initially performed only in case of sign of gravity (febrile torticollis, signs of sepsis, dyspnea, neurological signs, rapidly extensive evolution), and / or in children under 6 months of age or in the absence of clinical improvement after 48 to 72 hours of appropriate and wellmanaged intravenous antibiotic therapy [14]. The differential diagnosis of a suppurative adenitis arises with a congenital superinfected cyst. Localization of the mass is the first element of orientation: the subhyoidal median masses will rather evoke a cyst of the infected thyroglossal tract, whereas a sub-mental mass will evoke more an adenitis than a dermoid cyst and in the end the masses under maxillary can evoke a cyst of second branchial arch. In case of doubt, doppler-energy ultrasound can differentiate between adenopathy and cyst: in the first case there is a rich hilar vascularization, even in case of central necrosis, whereas in the second case the vascularization is poor and only peripheral $[1,7,12,13]$.

\section{Bacteriological data}

A sampling of pus for bacteriological examination must be carried out before any antibiotic treatment because in all the series, a high rate of decapitated infection was found, including our study $[1,2,4,10,11]$. In the literature, the most frequently found germs are Staphylococcus aureus and Staphylococcus pyogenes which is consistent with our results $[1,3,4,7,11,15,16]$. However, other organisms can rarely be isolated, such as Streptococcus pneumoniae, Haemophilus influenzae, and more rarely Klebsiella pneumoniae, Escherichia coli and anaerobic bacteria Fusobacterium, Prevotella $[1,10,11,15,16]$.

\section{Therapeutic aspects}

Medical treatment consists first of allin probabilistic intravenous antibiotic therapy which should target Staphylococcus aureus, Group A streptococcus and anaerobic germs of the oropharyngeal commensal flora. Since amoxicillin alone or in combination with clavulanic acid has the best sensitivity profile, first-line use is recommended in most medium-grade ORL infections $[14,17,18]$. Antibiotic therapy will be rehabilitated to antibiogram as soon as the germ is known. The oral relay started as soon as the general signs are gone, and the local signs have sufficiently regressed [19]. In our series, incision-drainage with local anesthesia combined with probabilistic intravenous antibiotic therapy was consistently 
performed in 66 patients with suppurative adenitis. On the other hand, in Francois M's series [1], drainage was not systematically performed because some patients had benefited only from a puncture associated with antibiotic therapy. Some authors [20] have proposed a puncture under ultrasound guidance with placement of a catheter to make other aspirations [1]. When adenitis is not collected, parenteral antibiotic therapy alone is performed. The first-line antibiotics used are amoxicillin-clavulanic acid, penicillin $G$, and third generation cephalosporins in combination with metronidazole $[14,17,18]$. This was the case of 17 patients with a simple adenitis in our series. The average duration of parenteral antibiotic therapy in our practice in case of surgical drainage is 5 days, which agrees with the data in the literature [1].

\section{Conclusion}

Acute adenitis is a common pediatric otorhinolaryngological condition. It is often secondary to infections of the oropharyngeal sphere, dental and skin diseases. The treatment is essentially based on antibiotic therapy combined with surgical drainage in case of purulent collection. The treatment of the portal of entry is imperative to avoid recurrence.

\section{Conflict of Interest: None}

\section{References}

1. Françoic M, Mariani KurkdjianP, Elbakkouri W (2004) Suppurative cervical adenitis in children A series of 45 cases. Ann Otolaryngol Chir Cervicofac 121: 110-114.

2. Dufour X, Gohler C, Bedier A (2004) Retro and lateropharyngeal abscesses in children. Ann Otolaryngol Chir Cervicofac 126(3): 327-333.

3. Ondzotto G, Fouemina T, Oko A (2009) Childhood Laterocervical abscess in a fistulized child in the pharynx: a case report. Arch Pediatrician 16: 1562-1564.

4. Faye PM, Ndongo AA, Gueye M (2014) Retro and parapharyngeal abscesses in children: diagnostic and therapeutic features in a pediatric hospital in Dakar. Medicine from Black Africa 61: 544-549.

5. Wagner R, Espitalier F, Madoz A (2009) Retro- and parapharyngeal abscesses in children: factors predicting medical treatment failure. Ann Otolaryngol Chir Cervicofac 126 : 112-119.
6. Bouhdadi S, Bouskraoui M (2008) Cervical lymphadenopathy in children. [State odotoring thesis]. Marrakech: Faculty of Medicine and Pharmacy.

7. Melenotte C, Edouard S, Lepidi H (2015) Diagnosis of infectious adenitis. J revomed 4: 1-9.

8. Husson B, Portier F (2005) Childhood cervical infections. Radiology Leaflets 45: 107-113.

9. James MC, Geoffrey SG, Romy DY (2004) Age-, Site-, and Time-Specific Differences in Pediatric Deep Neck Abscesses. Arch Otolaryngol Head Neck Surg 130: 201-207.

10. Lung C, Hsin C, Nan-C (2010) Deep Neck Infections in Different Age Groups of Children. J Microbiol Immunol Infect 43: 47-52.

11. Fédérici S, Silva C, Maréchal C (2009) Retro- and parapharyngeal infections: towards a harmonization of practices. Arch Pediatrician 16: 1225-1232.

12. Papakonstantinou O, Bakantaki A, Paspalaki P (2009) High-Resolution and Color Doppler Ultrasonography of Cervical Lymphadenopathy in Children. Acta Radiologica 42: 470-476.

13. Cassagneau P, Varoquaux A, Moulin G (2011) Exploration radiologique des infections cervico-faciales. J Jradio 92: 1015-1028.

14. Lorrot M, Haas H, Hentgen V (2013) Antibiotic therapy for severe ENT infections in infants and children: peripharyngeal infections. Arch Pediatrician 20: e1-S4.

15. Simo R, Hartley C, Rapado F (1998) Microbiology and antibiotic treatment of head and neck abscesses in children. Clin. Otolaryngol 23 164-168.

16. Sheila RK, Balakrishnan, Swathy JC (2017) clinical presentation and bacteriological study of deep neck space abscess. J evolution med dent sci 6: 193-200.

17. Grimpre E, Hentgen V, Lorrot M (2013) Antibiotic therapy for severe ENT infections of infants and children: therapeutic proposals from the Pediatric Infectious Pathology Group (GPIP) of the French Pediatric Society. Arch Pediatrician 20: e14-S19.

18. Haas H (2008) Antibiothérapie probabiliste aux urgences dans les abcès de la tête et du cou de lenfant. Arch Pédiatrie 15: 495-497.

19. Lescanne E, Sibel JP, Gendre C (1998) les tuméfactions inflammatoires aigues du cou de lenfant. J Pédiatr Puériculture 11: 451-462.

20. Yusa H, Yoshida H, Ueno E (2002) Ultrasound-guided surgical drainage of face and neck abscesses. J. Oral Maxillofac. Surg 31: 327-329.
This work is licensed under Creative Commons Attribution 4.0 License

To Submit Your Article Click Here: Submit Article
DOI: $10.32474 /$ SJ0.2020.05.000217

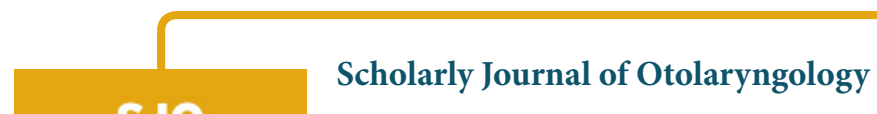

\section{Assets of Publishing with us}

- Global archiving of articles

- Immediate, unrestricted online access

- Rigorous Peer Review Process

- Authors Retain Copyrights

- Unique DOI for all articles 